\title{
Improving the energy efficiency of an electrodialytic process to extract phosphorus from municipal solid waste digestate through different strategies
}

Oliveira, Verónica; Kirkelund, Gunvor Marie; Horta, Carmo; Labrincha, João; Dias-Ferreira, Celia

Published in:

Applied Energy

Link to article, DOI:

10.1016/j.apenergy.2019.03.175

Publication date:

2019

Document Version

Peer reviewed version

Link back to DTU Orbit

Citation (APA):

Oliveira, V., Kirkelund, G. M., Horta, C., Labrincha, J., \& Dias-Ferreira, C. (2019). Improving the energy efficiency of an electrodialytic process to extract phosphorus from municipal solid waste digestate through different strategies. Applied Energy, 247, 182-189. https://doi.org/10.1016/j.apenergy.2019.03.175

\section{General rights}

Copyright and moral rights for the publications made accessible in the public portal are retained by the authors and/or other copyright owners and it is a condition of accessing publications that users recognise and abide by the legal requirements associated with these rights.

- Users may download and print one copy of any publication from the public portal for the purpose of private study or research.

- You may not further distribute the material or use it for any profit-making activity or commercial gain

- You may freely distribute the URL identifying the publication in the public portal 


\title{
Improving the energy efficiency of an electrodialytic process to extract phosphorus from municipal solid waste digestate through different strategies
}

\author{
Verónica Oliveira $^{1,2^{*}}$, Gunvor M. Kirkelund ${ }^{3}$, Carmo Horta ${ }^{4}$, João Labrincha² ${ }^{2}$ Celia Dias-Ferreira ${ }^{1,2,5}$ \\ ${ }^{1}$ College of Agriculture, Polytechnic Institute of Coimbra \& CERNAS, Bencanta, 3045-601 Coimbra, \\ Portugal \\ ${ }^{2}$ Materials and Ceramic Engineering Department, CICECO, University of Aveiro, Campus \\ Universitário de Santiago, 3810-193 Aveiro, Portugal \\ ${ }^{3}$ Department of Civil Engineering, Technical University of Denmark, building 118, 2800 Kgs. \\ Lyngby, Denmark \\ ${ }^{4}$ College of Agriculture, Polytechnic Institute of Castelo Branco \& CERNAS, Quinta da Senhora de \\ Mércules, 6001-909 Castelo Branco, Portugal \\ ${ }^{5}$ Universidade Aberta, Lisboa, Portugal \\ *corresponding author. Tel.: +351 239802600 Fax: +351 239802979 E-mail address: \\ veronica.oliveira@esac.pt
}

\begin{abstract}
This work assesses the possibility of energy optimisation during the electrodialytic extraction of phosphorus from the municipal solid waste digestate. Strategies tested for energy optimisation consisted in (i) using a dual-stage extraction approach; (ii) replacement of continuous stirring by pulse stirring and; (iii) utilisation of pulse electric current as an alternative to a constant current. Experiments were carried out using different stirring profiles (continuous stirring, pulsed stirring, manual stirring and no stirring) and different profiles for generating the electric field (continuous current and pulsed current). Dual-stage approach decreased the energy consumption by $30 \%$. Energy was mainly used in the stirring operation (80\%). Applying this strategy caused a faster acidification of the waste suspension and reduced the time required for the extraction. As for the second strategy, use of pulse stirring, it is possible to save energy by operating the stirrer $25 \%$ of the time, without compromising the phosphorus extraction values, which are close to $90 \%$. Corresponding energy savings reached $70 \%$. The third strategy tested, use of pulse current, had as side-effect a significant decrease of the phosphorus extracted, so the implementation of pulse current is not recommended. Overall, the energy efficiency of the
\end{abstract}


electrodialytic extraction of phosphorus can be improved by $80 \%$ through the use of the dual-stage approach and the use of stirring for $25 \%$ of the time. There is also a potential in further reducing the energy use by further improving the stirring system.

\section{Keywords}

Current; Stirring; Electrodialytic process; Municipal solid waste; Phosphorus extraction; Energy consumption.

\section{Introduction}

Fertilisers are crucial to sustain the world's food production. Worldwide, 263 million metric tonnes of phosphate rock were mined in 2017 [1], most of which used to produce phosphorus fertilisers. Mining of phosphate rock requires huge amount of energy, namely for the operation of energy-intensive equipment, such as draglines, drillers, blasters, shovels, pumps, screeners, crushers, dryers and loaders, as well as in the transportation of materials. Each tonne of phosphorus fertilizer $\left(\mathrm{P}_{2} \mathrm{O}_{5}\right)$ produced requires the extraction of approximately 13 tonnes of material, of which only $1 / 3$ is phosphate rock and the remaining are mostly clay and silt [2]. According to BCS Incorporated [3], the total energy required to mine and process phosphate is $20.71 \mathrm{kWh} \mathrm{t}^{-1}$ of beneficiated phosphate rock (for a surface mine in the USA), of which mining represents $98 \%$ and beneficiation (initial removal of impurities from phosphate rock ore) the remaining $2 \%$.

While the mining of phosphorus from virgin phosphate ore is an energy-intensive process, phosphorus is present in several waste materials and is widely and freely available from centralised waste treatment facilities. Novel processes to extract phosphorus from waste and transform it into raw products are emerging. In such processes the mining of phosphate rock is avoided, leading to potentially huge energy savings in the manufacturing of mineral fertilisers. The production of phosphorus from secondary sources is in line with the European Union strategy of promoting a low-energy economy and the development of low-carbon technologies [4].

Recently, Oliveira et al. [5] proposed a process to extract phosphorus from the municipal solid waste (MSW) digestate, followed by its transformation into struvite, a phosphorus-based fertiliser used in agriculture. The electrodialytic (ED) process used for the extraction, still at laboratory scale, can extract $90 \%$ of the phosphorus present in the MSW digestate, thus being highly promising in terms of phosphorus recovery. The principle of ED process has been explained elsewhere [6]. Briefly, during the ED process, the separation of the charged ions contained in a waste matrix is induced by an electric field [7]. In practice, the negatively-charged species (e.g. phosphate) are attracted to the anode and move out from the waste chamber through an anionic exchange membrane, whereas the positively-charged species 
(e.g. metals) are attracted to the cathode and move out from the waste compartment through a cationic exchange membrane (Fig. 1). The advantage of this membrane-based separation process is that the ions only move in one way (i.e. out of the waste matrix chamber), which means no energy is wasted for transporting ions from the electrode chambers into the waste matrix chamber [8]. However, it consumes a reasonable amount of energy to generate the electric field and also in stirring the waste suspension. Energy usage can have a huge impact on operating costs, strongly affecting the economic sustainability of the phosphorus extraction and recovery process.

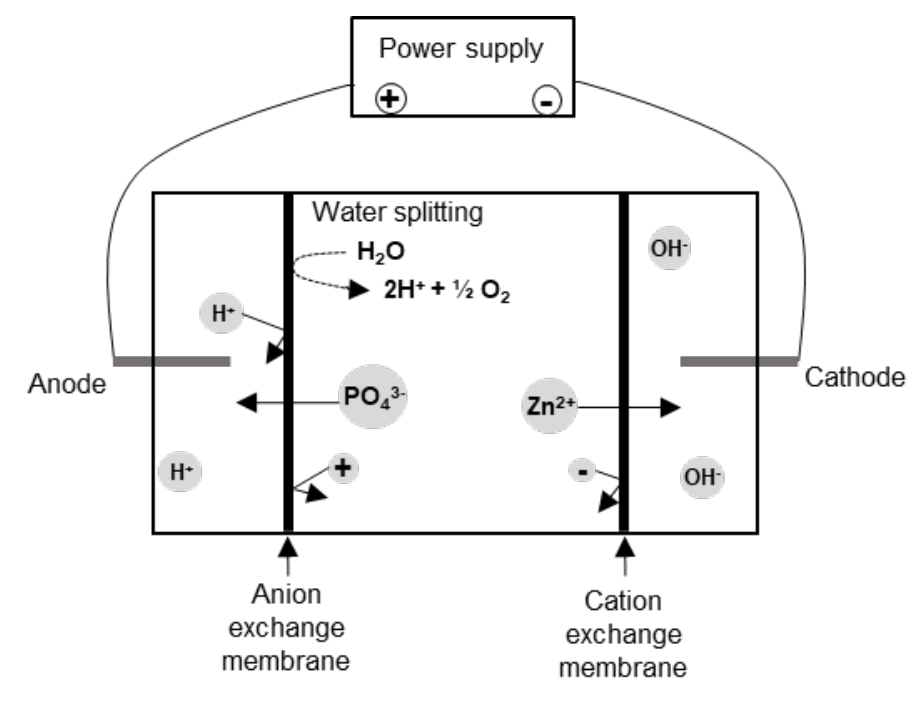

Fig. 1 Principle of the ED process

Several processes have been used to extract phosphorus from different waste streams. For instance, Jung et al. [9] reported the application of a thermo-chemical process to extract phosphorus from $\mathrm{CaO}-\mathrm{SiO}_{2}-$ $\mathrm{CaF}_{2}$ slag for optimised refinement of solar grade silicon. Tan and Lagerkvist [10] reviewed different leaching technologies (e.g. bioleaching, chemical or supercritical extractions) used to extract phosphorus from biomass ash. The struvite crystallisation technique has been used for the recovery of phosphorus from slaughterhouse wastewater [11]. Microbial fuel cells have been recently applied to recover phosphorus from wastewater through electrochemical precipitation [12] and mathematical modelling approaches have been employed to optimise the power density and the phosphorus recovery [13]. A photosynthetic microbial fuel cell [14] and microalgae techniques were also used to extract phosphorus from wastewater [15] and human urine [16]. Furthermore, an hydrothermal carbonisation process has been carried out to recover phosphorus from an anaerobic granular sludge [17]. Phosphorus has also been extracted from sewage sludge [18] and sewage sludge ash [19] using an electro-membrane technique. However, the above studies did not study the utilisation of energy for the phosphorus extraction nor on its optimisation. The current work is a contribution to fill this gap by providing an understanding of where the energy is used during the ED extraction of phosphorus from a waste and by testing different strategies to reduce this energy usage. 
The use of pulse current has been referred as one feasible approach to decrease the energy input during ED extraction of heavy metals [20]. Sun et al. [21] found that the energy consumption could be decreased by using low frequency pulse current (about $70 \%$ ). Sun and Ottosen [8] demonstrated that pulse current with a higher density enhanced the ED removal of heavy metals and decreased the energy consumption (60\% - 67\%). The use of high frequency pulse current also decreased the energy consumption of ED removal of heavy metal from soils (11\% - 33\%) [22]. Even though the use of pulse current has been successful for the extraction of metals, so far it has not been tested for phosphorus extraction.

Another improvement is related to the energy consumption upon stirring the waste during the extraction. This operation strongly enhances the phosphorus extraction yields [5] in comparison with a stationary cell [23], emphasizing the need of using a stirrer. Previously, Ottosen et al. [24] referred the possibility of saving energy by applying a pulse stirring of 4 times $1 \mathrm{~h}$ a day on ED extraction of phosphorus from sewage sludge ash. However, the impact of this measure on the energy consumption profiles of the process was not assessed.

The current work looks at opportunities to make the ED extraction of phosphorus from MSW digestate more energy-efficient, without compromising the amount of phosphorus extracted. The strategies tested are three-fold: i) to introduce a dual-stage approach to reduce the overall time required for the extraction; ii) a replacement of continuous stirring by pulse stirring, while assessing the impact on the energy usage; and iii) the utilization, for the first time, of pulse current during phosphorus extraction, and monitoring its effect on extraction yields.

The findings of the current work will contribute to improve the energy efficiency of the ED extraction of phosphorus, reducing greenhouse gas emissions and operating costs. In addition, it also contributes to alleviate the energy dependence of the fertiliser-manufacturing industry by allowing to efficiently reuse phosphorus from waste as a replacement for the mining of virgin phosphate ores.

\section{Materials and methods}

\subsection{ED phosphorus extraction}

The ED apparatus used for phosphorus extraction is shown in Fig. 2. The apparatus has three cylindrical chambers made of Plexiglas ${ }^{\circledR}$ with an internal diameter of $8 \mathrm{~cm}$. The waste chamber was $10 \mathrm{~cm}$ long and the two electrode chambers were $5 \mathrm{~cm}$ long each. An anion exchange membrane (204 SZRA B02249C, from IONICS) was placed between the anode chamber $\left(^{+}\right)$and the waste chamber while a cation exchange membrane (CR67 HUY N12116B, from IONICS) was used to separate the waste chamber from the cathode chamber (-). 

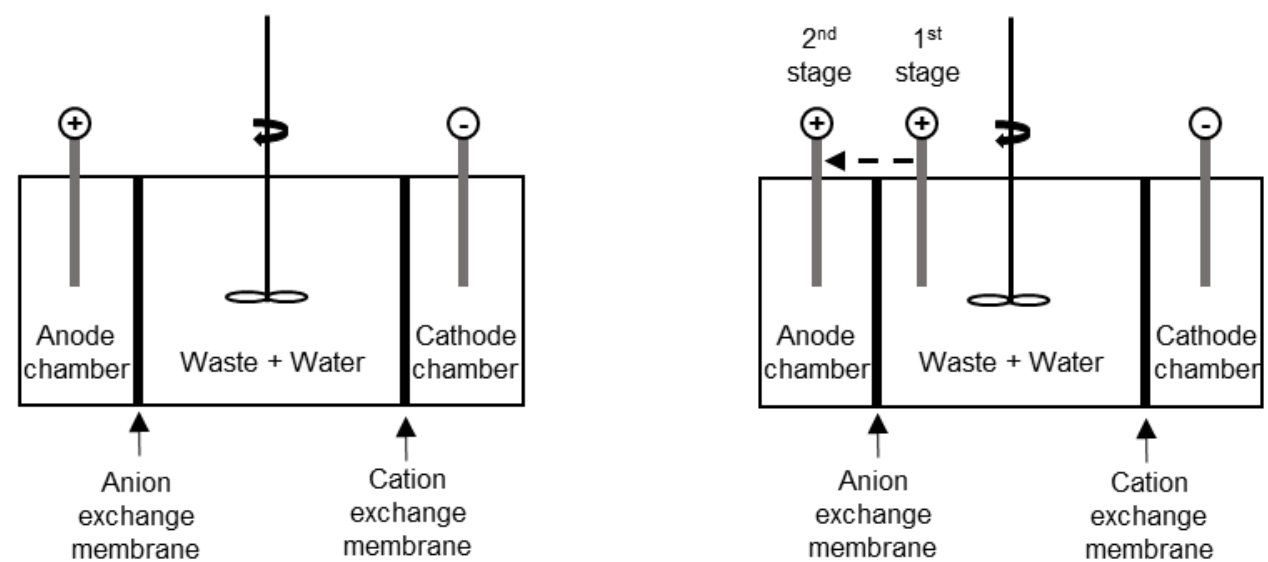

Fig. 2 Electrodialytic apparatus used in a) single- and b) dual-stage extraction experiments

At the beginning of the experiments, $35 \mathrm{~g}$ of MSW digestate and $350 \mathrm{~mL}$ of distilled water $\left(\mathrm{L}: \mathrm{S}=10 \mathrm{~mL} \mathrm{~g}^{-1}\right.$ ) were placed into the waste chamber. The MSW digestate was collected at a mechanical and biological treatment facility in Portugal, after centrifugation (on-site). It was transported to the laboratory, dried $\left(105^{\circ} \mathrm{C}, 24 \mathrm{~h}\right)$, grounded $(<1 \mathrm{~mm})$ and stored in closed containers until being used in the ED experiments. The total phosphorus content was $7.53 \pm 0.48 \mathrm{~g} \mathrm{~kg}^{-1}$ (dry weight), the electrical conductivity was $5.72 \pm 0.39 \mathrm{mS} \mathrm{cm}^{-1}$ and the $\mathrm{pH}$ ranged between $7.67-7.71$. The complete chemical characterisation can be found in Oliveira et al. [5].

A plastic flap fastened to a glass spatula connected to an overhead stirrer (VWR VOS - 45 W of electric power) was placed inside the waste chamber and used to stir the MSW digestate suspension. The anolyte and catholyte were $0.01 \mathrm{M} \mathrm{NaNO}_{3}$ (adjusted to $\mathrm{pH}<2$ with $\mathrm{HNO}_{3}$ ). Platinum coated titanium bars were used as electrodes (from Permascand ${ }^{\circledR}$ ), having $3 \mathrm{~mm}$ diameter and $5 \mathrm{~cm}$ length.

A current of $50 \mathrm{~mA}$ was applied using a power supply (E3612A, from Hewlett Packard, $30 \mathrm{~W}$ ) and the following parameters were monitored daily: electric current, voltage drop, $\mathrm{pH}$ in the electrolytes (anolyte and catholyte) and $\mathrm{pH}$ and electric conductivity in the MSW digestate suspension. The $\mathrm{pH}$ of the catholyte was manually adjusted to $<2$ by addition of $1: 1 \mathrm{HNO}_{3}$, in order to avoid the precipitation of metal hydroxides nearby the cation exchange membrane, which could hinder ionic transport through the ED cell [25].

At the end of the experiments, the MSW digestate suspension was filtered using quantitative filter paper. The volume of the liquid phase was registered, and the solid phase was dried in an oven at $105^{\circ} \mathrm{C}$, overnight. Ion exchange membranes and electrodes were soaked in $1 \mathrm{M}$ and $5 \mathrm{M} \mathrm{HNO}_{3}$, respectively during $24 \mathrm{~h}$. Contents of phosphorus were measured in the solid (after hand crushing in a mortar) and the liquid phase of the MSW digestate, soaking electrodes solutions, ion-exchange membrane cleaning solutions and electrolyte solutions. 
The phosphorus extraction efficiency was defined as the mass of phosphorus found in the anolyte solution compared to the total mass measured in all parts of the ED cell, at the end of the experiment.

\subsection{Experimental design}

The experiments were carried out in three series. In each series, the objective was to assess the effect of a specific operating condition on the energy usage and the percentage of phosphorus extracted. The first series (Table 1) comprised 2 experiments (single-stage vs dual-stage); the next series (Table 2) comprised $\underline{7 \text { experiments }}$ with different stirring times; and the last series (Table 3 ) comprised $\underline{6}$ experiments with different electric pulse profiles. A more detailed explanation of each series is presented next.

In the first series, STAGES (Table 1), a comparison was made between the common single-stage extraction against a novel dual-stage extraction previously used by Chen et al. [26]. In the single-stage experiment, the ED cell set-up used is shown in Figure 2 a). In this configuration, the MSW digestate suspension is placed into the waste chamber, whereas the electrode (+) and (-) are placed in the anode and cathode chambers, respectively. Under the electric field, the phosphorus charged species are moved from the waste chamber to the anode chamber whereas the positive charged species (e.g. metals) are transported to the cathode chamber. During the ED experiment, the acidification of MSW digestate suspension due to the electrolysis of water taking place at the surface of anion exchange membrane (water splitting) promotes the solubilisation of phosphorus. In the dual-stage experiments (Fig. 2b), the electrode $(+)$ is first placed in the waste chamber $\left(1^{\text {st }}\right.$ stage of extraction). In this stage of extraction, the acidification of the waste is due to the half-reaction at the anode (Eq. 1: $2 \mathrm{H}_{2} \mathrm{O} \rightarrow \mathrm{O}_{2}(g)+4 \mathrm{H}^{+}+4 e^{-}$) which contributes to a faster decrease of $\mathrm{pH}$. Thus, the phosphorus charged species remains in the waste chamber whereas the positive charged species are moved out of the waste chamber to the cathode chamber. When the $\mathrm{pH}$ reached 3 in the waste suspension, the electrode $(+)$ is moved into the anode chamber, and the $2^{\text {nd }}$ stage of the extraction initiates, during which phosphorus solubilised in the $1^{\text {st }}$ stage migrate under the electric field out from the waste chamber to the anode chamber.

Table 1 Experimental conditions in series STAGES.

\begin{tabular}{lllll}
\hline Experiment & Stirring & Current & Electrode (+) location & Duration \\
\hline Single-stage & $100 \%$ ON & Continuous at $50 \mathrm{~mA}$ & Anode chamber & $9 \mathrm{~d}$ \\
Dual-stage & $100 \% \mathrm{ON}$ & Continuous at $50 \mathrm{~mA}$ & $1^{\text {st }}$ stage: waste chamber & $7 \mathrm{~d}$ \\
& & & $2^{\text {nd }}$ stage: Anode chamber & \\
\hline
\end{tabular}

In the second series, named STIRRING, the objective was to assess the effect of different stirring time. For this purpose, the stirrer was turned ON/OFF at regular intervals (Table 2). A dual-stage approach was used in all experiments in this series, and the electric current was kept constant at $50 \mathrm{~mA}$ during $7 \mathrm{~d}$. 
Table 2 Experimental conditions in series STIRRING (50 mA; dual-stage approach).

\begin{tabular}{ll}
\hline Experiment & Stirring \\
\hline $100 \%$ stirring & Continuous \\
$75 \%$ stirring & Pulse: $45 \mathrm{~min}$ ON + 15 min OFF \\
$50 \%$ stirring & Pulse: $30 \mathrm{~min}$ ON + 30 min OFF \\
$25 \%$ stirring & Pulse: 15 min ON + 45 min OFF \\
$17 \%$ stirring & Pulse: 30 min ON + 150 min OFF \\
Manual stirring & $10 \mathrm{~s} \mathrm{~d}^{-1}$ \\
No stirring & none \\
\hline
\end{tabular}

In the third series, named CURRENT (Table 3), the effect of turning the electric field ON and OFF at regular intervals during the $7 \mathrm{~d}$ ED extraction was assessed. Similarly to the STIRRING series, a dualstage approach was used and the stirring profile was $15 \mathrm{~min}$ ON +45 min OFF.

Table 3 Experimental conditions in series CURRENT (pulse stirring: 15 min ON + 45 min OFF; dual-stage approach).

\begin{tabular}{ll}
\hline Experiment & Current \\
\hline $100 \%$ current ON & Constant at $50 \mathrm{~mA}$ \\
$80 \%$ current ON & Pulse: $60 \mathrm{~min}$ ON +15 min OFF \\
$75 \%$ current ON & Pulse: 45 min ON +15 min OFF \\
$67 \%$ current ON & Pulse: 30 min ON +15 min OFF \\
$50 \%$ current ON & Pulse: 15 min ON +15 min OFF \\
Mixed & $1^{\text {st }}$ stage: constant at $50 \mathrm{~mA} ;$ \\
& $2^{\text {nd }}$ stage: pulse: 30 min ON +15 min OFF \\
\hline
\end{tabular}

\subsection{Analytical methods}

$\mathrm{pH}$ and electric conductivity were measured using Radiometer electrodes. The total content of phosphorus in solid samples was measured in triplicate after a pre-treatment described in Danish Standard DS259: $1.0 \mathrm{~g}$ of dry sample was placed into a schott flask and $20.0 \mathrm{~mL}$ of 1:1 $\mathrm{HNO}_{3}$ was added. The flasks were heated in an autoclave at $200 \mathrm{kPa}\left(120^{\circ} \mathrm{C}\right)$ during $30 \mathrm{~min}$. Then the samples were filtered by vacuum through a $0.45 \mu \mathrm{m}$ filter and diluted to $50 \mathrm{~mL}$. A Varian 720-ES ICP-OES (Inductively Coupled Plasma-Optical Emission Spectrometry) was used to quantify the elemental concentration in pre-treated samples as well as in all samples resulting from ED experiments.

\subsection{Energy consumption calculation}

During ED experiments a power supply is used to generate a voltage drop between opposite sides of the waste compartment, thus creating an electric field and the passage of an electric current across the waste compartment. The energy used by the power source was calculated as [22]:

$$
E=\int V * I * d t \quad(\text { Eq. } 2)
$$


where $\mathrm{E}$ is the energy consumption (Wh), $V$ is the voltage drop between electrodes $(\mathrm{V}), I$ is the current (A) and $t$ is duration (h).

The MSW digestate in the central compartment is kept in suspension through the use of an overhead stirrer that promotes homogenisation and avoids deposition of material at the bottom of the cell. The energy consumption (Wh) by the stirrer was calculated as:

$E=P * t$

where $P$ is the electric power (W) and $t$ is the operation time of the equipment (h).

The power of the stirrer is $45 \mathrm{~W}$; however, the stirrer was adjusted to operate at $11.25 \mathrm{~W}$ (i.e. $1 / 4$ of total power).

The overall energy consumption of the ED process was calculated as the sum of the energy used by the power supply (Eq. 2) and the energy used by the stirrer (Eq. 3). The energy used for the pumps to circulate the electrolytes was not considered.

\section{Results and discussion}

\subsection{Effect of introducing a dual-stage approach on energy usage and phosphorus extraction}

One possibility to decrease the energy consumption of ED is to decrease the duration of the experiment by promoting a faster acidification of the MSW digestate suspension which consequently enables a faster solubilisation of phosphorus. Figure 3 compares the evolution of $\mathrm{pH}$ inside the waste chamber during the single-stage extraction against the dual-stage extraction.

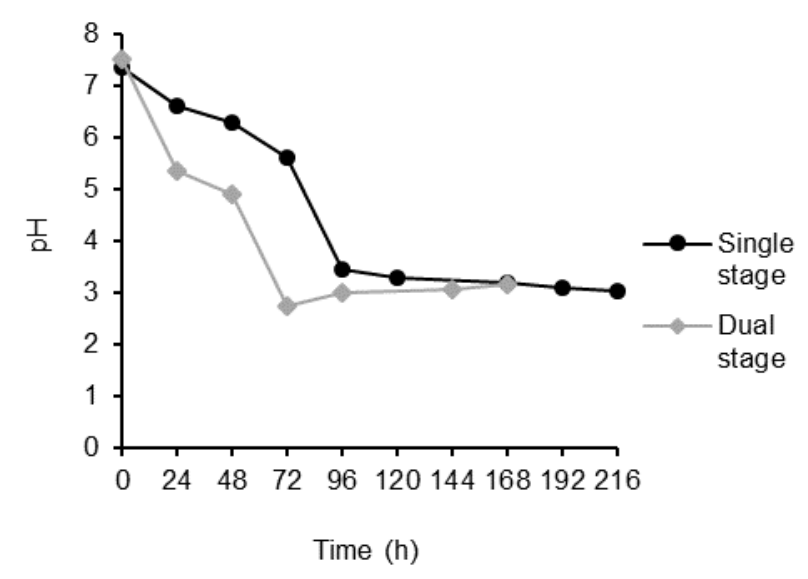

Fig. $3 \mathrm{pH}$ of MSW digestate suspension during single- and dual-stage extraction of phosphorus (50 mA, $100 \%$ stirring, $100 \%$ current)

The pH of the MSW digestate suspension decreased from the initial value (7 - 8) to about 3, during both the single and dual-stage extractions, but it decreased faster in the dual-stage extraction. This happened 
because during the first stage of the dual-stage extraction (first $72 \mathrm{~h}$ ), the anode was inserted directly into the waste chamber and $\mathrm{H}^{+}$ions were generated there (Eq. 1), whereas in the single-stage extraction $\mathrm{pH}$ decreased slower, as a result of water splitting at the surface of the anion exchange membrane, a phenomenon previously described in [7].

The energy usage during the single- and dual-stage extraction is shown in Fig. 4.
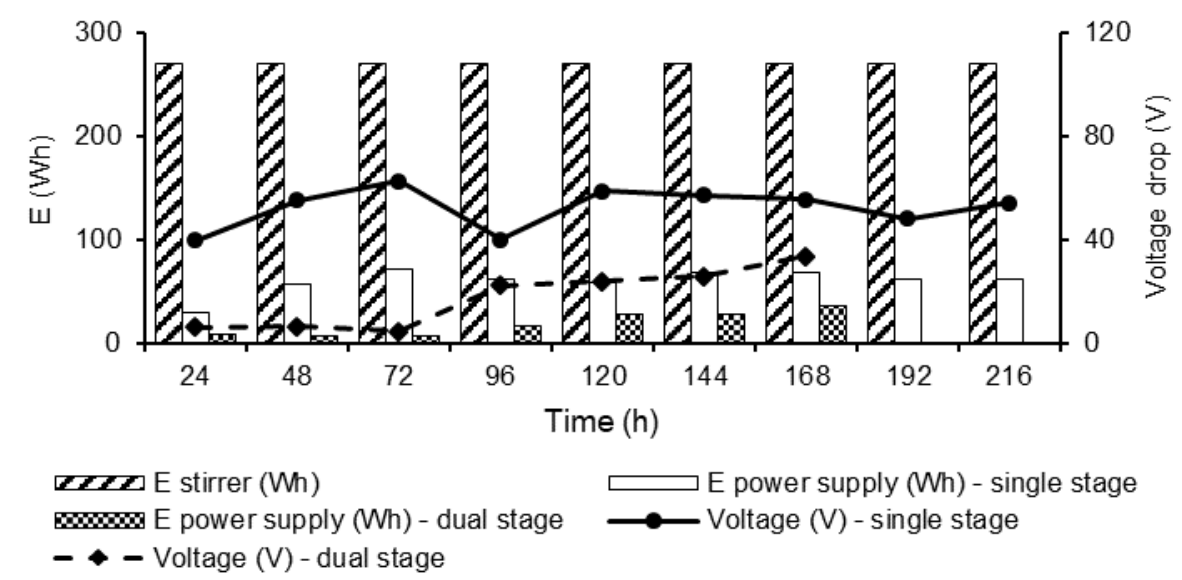

Fig. 4 Energy used per day and voltage drop in the waste compartment during the single- and dual-stage ED extraction experiments using continuous stirring under a constant electric field of $50 \mathrm{~mA}$ (experimental series: STAGES)

Stirring used up a constant amount of energy per day of approximately $270 \mathrm{Wh}$, totalling approximately $1900 \mathrm{Wh}$ for the dual-stage experiment and approximately $2400 \mathrm{Wh}$ for the single-stage experiment (2 d longer).

The energy used by the power supply to generate the electric field was not constant during the dualstage experiment. When the $2^{\text {nd }}$ stage of extraction of the dual-stage experiment started ( $72 \mathrm{~h}$ ), there was an increase of voltage drop which contributes to an increase of energy used by the power supply. This is explained by the depletion of charged ions caused by their migration under the electric field towards the anode chamber (Fig. 1). During the single-stage experiment, as the anode is kept in the anode chamber, a continuous ionic migration occurred, and the voltage drop was high throughout the experiments resulting in higher energy usage by the power supply (daily average of approximately $60 \mathrm{Wh}$, totalling about $540 \mathrm{Wh}$ ) than in the dual-stage experiment (daily average of approximately $20 \mathrm{Wh}$ totalling approximately $130 \mathrm{Wh}$ ).

Overall, the stirring applied to keep the MSW digestate in suspension was the major energy consumer, ranging from $79 \%$ to $98 \%$ of the total daily energy used. This highlights the importance of reducing the stirrer usage during the experiments by turning ON the stirrer only at specific periods (application of pulse stirring), as assessed in section 3.2.

The phosphorus extractions were practically the same in the single-stage (90\%) and dual-stage experiments (89\%). However, the single-stage experiment was $2 \mathrm{~d}$ longer and required higher energy, 
because the voltage over the cell was higher. Therefore, the amount of energy required to extract $1 \mathrm{mg}$ of phosphorus is about $50 \%$ higher in the single-stage $\left(13.8 \mathrm{Wh} \mathrm{mg}^{-1}\right)$ than in the dual-stage experiment (8.6 Wh mg-1). In practice, this means that the extraction of phosphorus using a dual-stage approach is more energy efficient.

\subsection{Replacement of continuous stirring by pulse stirring}

\subsubsection{Energy usage}

Figure 5 shows the energy consumption in the experimental series STIRRING, which tested the effects of different stirring times in dual-stage ED phosphorus extraction experiments. The energy used by the stirrer is directly proportional to the time the stirrer is turned ON. The amount of energy used by the power supply to generate the electric field was similar in all experiments using mechanical stirring but higher in the experiments with manual stirring and no-stirring.

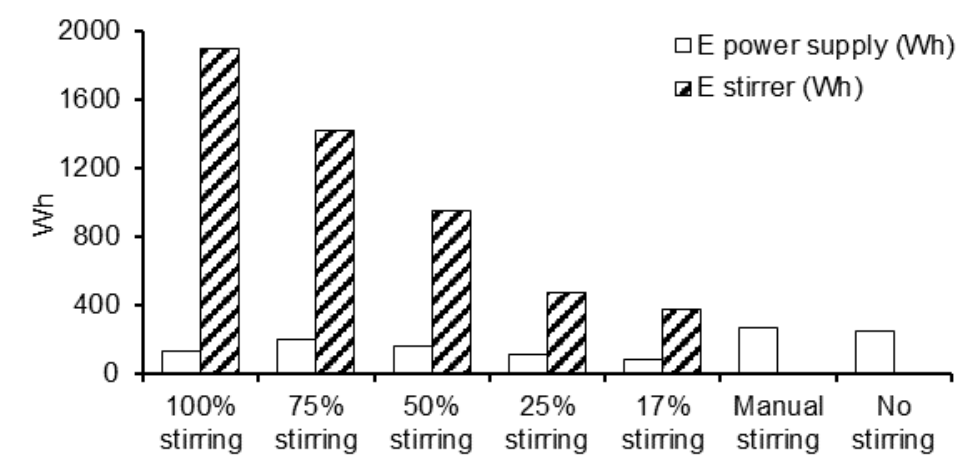

Fig. 5 Total energy consumption (Wh) for experimental series STIRRING

A higher electrical resistance was generated in the manual and no-stirring experiments, when compared to mechanical stirred experiments, because stirring facilitates the dissolution of charged species from the MSW digestate. In the manual and no-stirring experiments, to maintain the current at the preestablished value of $50 \mathrm{~mA}$, the power supply automatically increased the voltage drop (Fig. 6a), resulting in a higher energy consumption. In experiments with manual stirring the voltage jump occurred after $48 \mathrm{~h}$ while in the experiments without stirring it was observed after $24 \mathrm{~h}$ (Fig. 6a). In the experiments with mechanical stirring the voltage drop was low during the first days of the experiments and increased after $72 \mathrm{~h}$ (Fig. 6a), when the anode was moved from the central to the anode compartment. The increase in voltage drop was caused by the depletion of charged ions in the MSW digestate suspension, which decreased the electric conductivity in the MSW digestate suspension (Fig. 6b). 

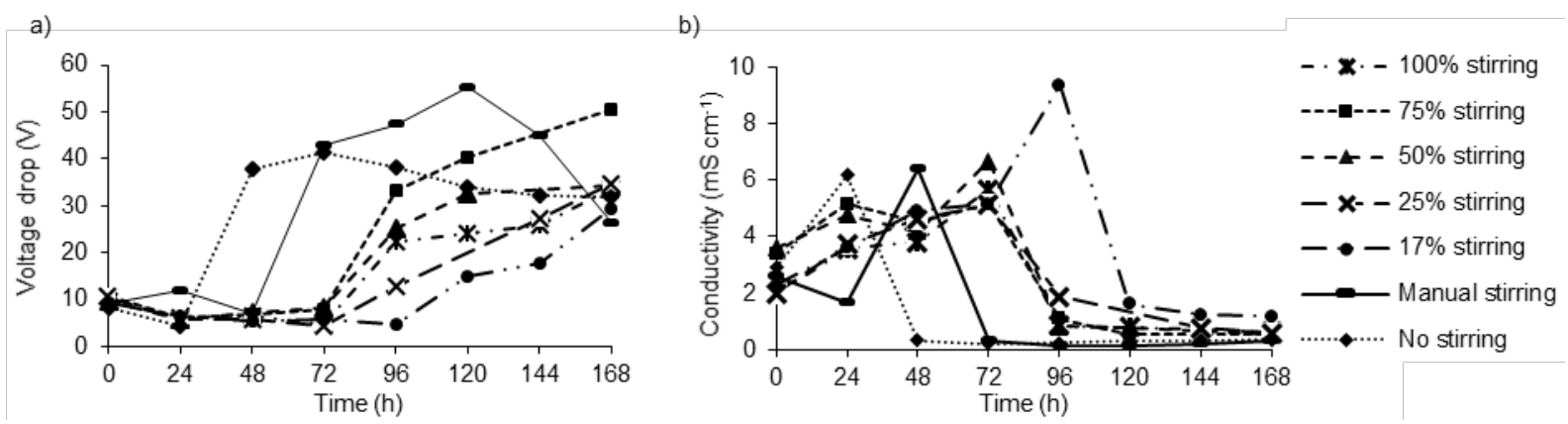

Fig. 6 Variation of voltage drop a) and electric conductivity in the MSW digestate suspension b) for experimental series STIRRING

\subsubsection{Phosphorus extraction efficiencies}

The mass balance of phosphorus, defined as the amount of phosphorus found at the end of the experiment compared to the initial amount in the MSW digestate, varied between $78 \%$ and $108 \%$, which were considered to be acceptable.

Figure 7 shows the phosphorus extraction obtained at the end of ED experiments, where the effects of pulse stirring were tested. The reduction of stirring time from continuous to $75 \%, 50 \%$ or $25 \%$ did not affect the phosphorus extraction ( $\approx 88 \%$ ). This demonstrates that about $20 \%$ (exp. 75\% stirring), $45 \%$ (exp. 50\% stirring) or $71 \%$ (exp. 25\% stirring) of energy usage during the ED extraction of phosphorus can be saved. Previously, Ottosen et al. [24] reported that stirring could be reduced to only 4 times $1 \mathrm{~h}$ a day (circa $17 \%$ stirring) without affecting extraction of phosphorus from sewage sludge ash. However, in the current work, if the stirring time went below $15 \mathrm{~min} / \mathrm{h}$ (25\%), the phosphorus extraction was reduced from $88 \%$ to $66 \%$ (representing a reduction of $37 \%$ ). The operation of the stirrer is important for the phosphorus extraction because it enhances the electro-migration of charged ions species by the fastest route, avoiding the extra time needed by the ions to find a way around the waste particles (or air) present in the waste matrix when the stationary ED cell is used [22]. For instance, the distance $\mathrm{H}^{+}$ions have to migrate is shorter in a stirred than in stationary ED cell [22]. In addition, stirring could have impacts on the speciation of some elements by increasing the redox potential in waste solution, which could affect its removal [22].

In previous work, the use of a stirred ED cell achieved higher phosphorus extraction values, when compared to the stationary system [5]. Looking at Fig. 7 it is now possible to sustain that among the different stirring profiles tested in the current work, the best one to achieve the highest extraction with the lowest energy consumption (using the dual-stage approach) is $15 \mathrm{~min} / \mathrm{h}$ (25\% stirring). This stirring profile used almost 4 times less energy than the continuous stirring, without affecting the phosphorus extraction yields. 


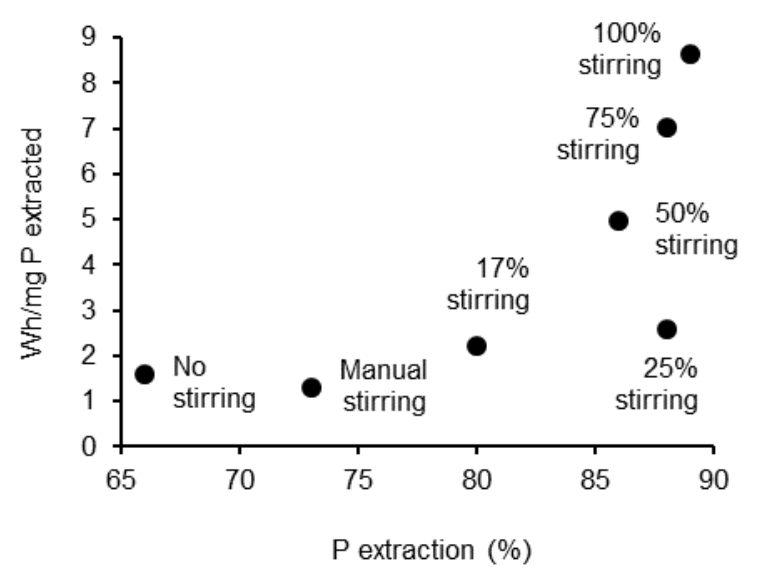

Fig. 7 Phosphorus extracted (\%) and energy consumption per mg of phosphorus extracted for experimental series STIRRING

\subsection{Use of pulse current as alternative to constant current}

\subsubsection{Energy usage}

Figure 8 presents the energy consumption for each experiment in the series CURRENT. Even though these experiments were carried out using 15 min stirring/h (demonstrated in section 3.2 as the most efficient stirring profile), the amount of energy used by the stirrer is still about 3 to 10 times higher than the energy consumed by the power supply for the generation of the electric field. The experiments of this series did not focus on the stirrer consumption though, instead aimed at evaluating the possibility of reducing the energy usage by the power supply.

As referred in section 3.2.1, the energy consumed in the generation of the electric field is influenced by the resistance (voltage drop) of the solution inside the waste compartment. The energy consumption by the power supply is also dependent on the time it is turned ON. The experiment $15 \mathrm{~min}$ ON and $15 \mathrm{~min}$ OFF is the one for which the voltage drop values were lowest (Fig. 9) and also the one where the power supply was turned ON the least time (50\%). It is thus the experiment with the lowest energy consumption in this series (Fig. 8).

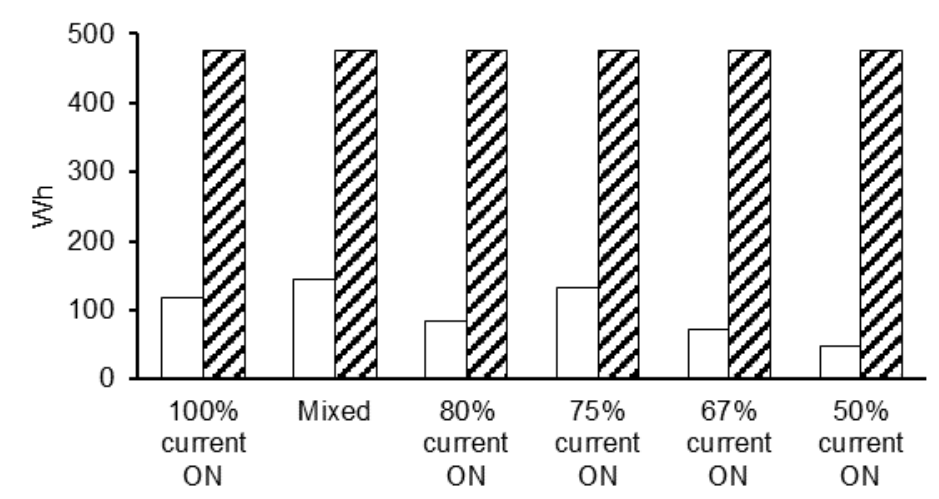

口E power supply $(\mathrm{Wh}) \quad \square \mathrm{E}$ stirrer $(\mathrm{Wh})$ 


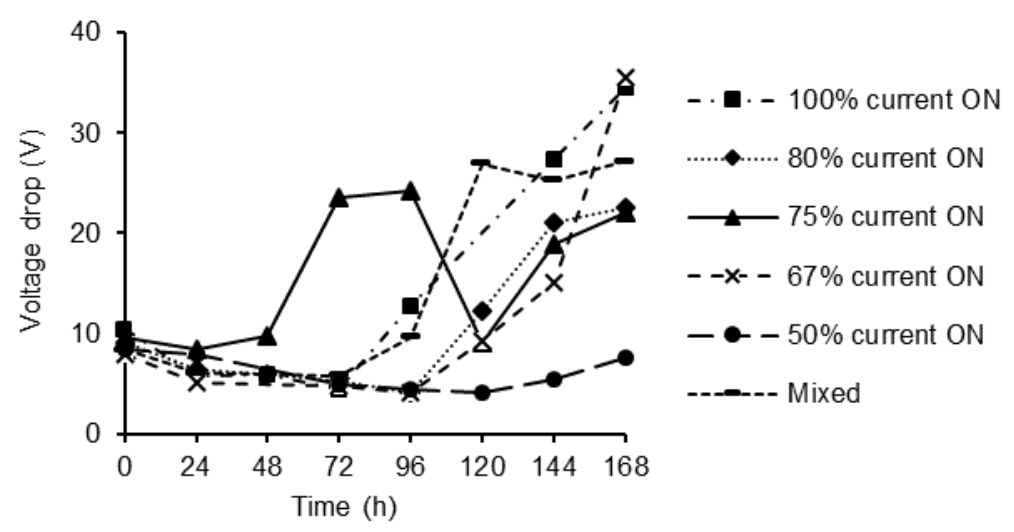

Fig. 9 Variation of voltage drop across the cell for experimental series CURRENT

\subsubsection{Phosphorus extraction}

The effect of the different pulse current schemes on ED extraction of phosphorus is shown in Fig. 10. Phosphorus extraction decreased from $89 \%$ to $37 \%$, when the current is changed from constant (100\% current $\mathrm{ON}$ ) to pulse mode (50 \% current $\mathrm{ON}$ ).

During the ED extraction process, the electric current influences two main phenomena: i) the electromigration of the negative and positive charged species present in the MSW digestate suspension from the waste chamber into the anode or cathode chambers, respectively and; ii) the acidification of the MSW digestate suspension. The latter option is the major contributor affecting the mobility of charged species dissolved from the waste. Based on previous work [5], the extraction of phosphorus from MSW digestate requires a $\mathrm{pH}$ range of 2.5 - 3.0 during the experiments, in order to promote the continuous dissolution of phosphorus contained in the MSW digestate suspension. Figure 11 shows that in 100\% current $\mathrm{ON}$ and mixed current experiments, the decrease of $\mathrm{pH}$ of suspension to about 3.0 was faster than in the other four experiments of the series CURRENT. In the experiments using only pulse current, an additional $24 \mathrm{~h}$ and $48 \mathrm{~h}$ were required to achieve similar $\mathrm{pH}$ values. Overall, there was a reduction of the phosphorus extraction efficiency in all pulse current experiments as well as in the mixed current experiment. Therefore, under the experimental conditions tested in the current work, the use of a constant current is required. Otherwise, phosphorus extraction from MSW digestate is compromised. 


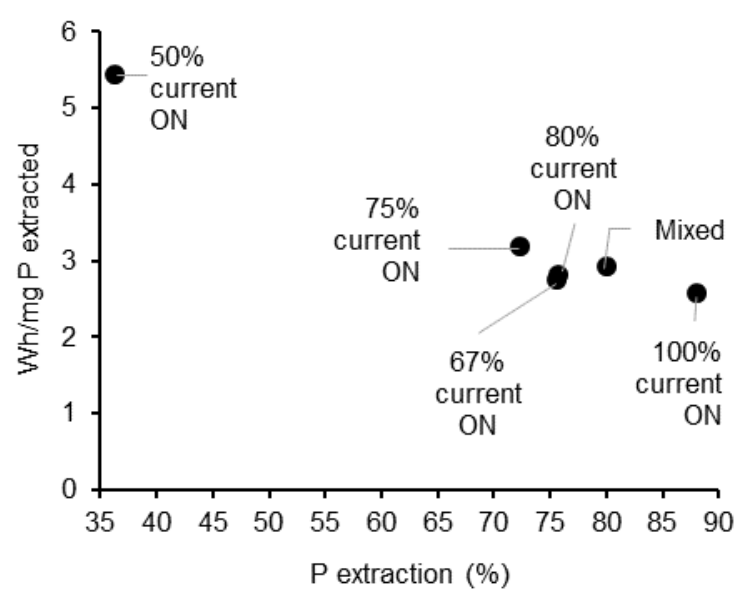

Fig. 10 Phosphorus extraction (\%) and energy consumption per mg of phosphorus extracted obtained for experimental series CURRENT

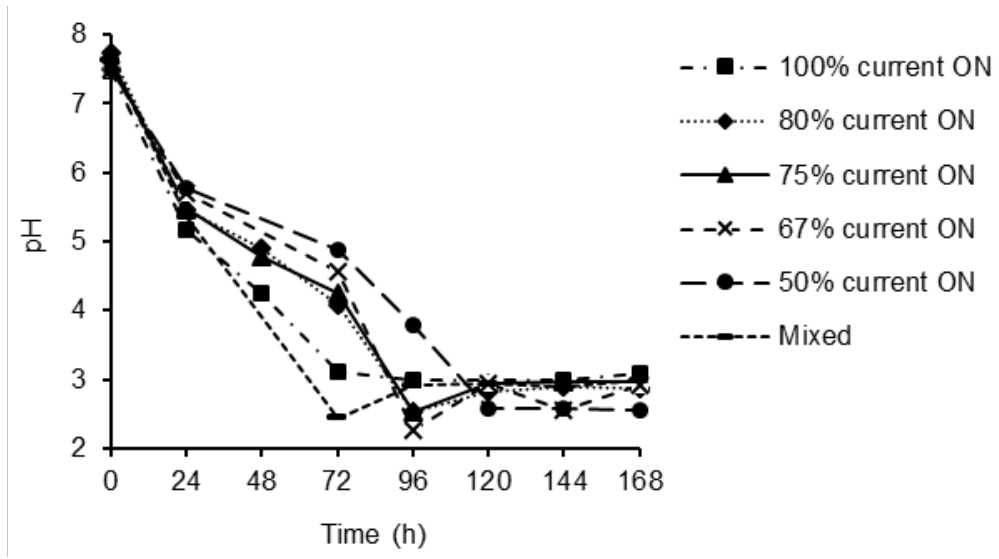

Fig. 11 Evolution of pH in MSW digestate suspension during experimental series CURRENT

\section{Conclusions}

The current work focused on energy optimisation of the electrodialytic extraction of phosphorus from municipal solid waste digestate in laboratory scale.

The energy was mainly used in the stirring operation (more than $80 \%$ ) while less than $20 \%$ was used in the generation of the electric field required for the electro-extraction of phosphorus. The proposed strategy of using a dual-stage approach (in which the anode is first placed inside the waste compartment and then moved into the anode chamber) resulted in energy savings of circa $30 \%$, mostly because a faster acidification of municipal solid waste digestate suspension occurred, allowing the hydraulic retention time to be reduced from $9 \mathrm{~d}$ to $7 \mathrm{~d}$. Moreover, after testing different stirring profiles it was demonstrated that it is also possible to save energy during electrodialytic extraction of phosphorus by operating the stirrer during $25 \%$ of the time $(15 \mathrm{~min} / \mathrm{h})$, without compromising the phosphorus 
extraction values. Savings by introducing this measure reached $70 \%$. Finally, the third strategy tested, pulse current, that consisted in turning off the power supply during regular intervals, had as side-effect a significant decrease of the phosphorus extraction, so the implementation of pulse current is not recommended, and a constant current should be used.

The lab-scale of the electrodialytic apparatus used in the current work does not allow a fair comparison between the energy consumption (per kg of phosphorus extracted) of the electrodialytic technique with other already well-established technologies. Full-scale processes have been comprehensively optimized and the larger scale allows for efficiency gains not possible at smaller scales. For these reasons, a comparison with other techniques should only be addressed in future works. Overall, the energy efficiency of the electrodialytic extraction of phosphorus can be improved by approximately $80 \%$ by using the dual-stage approach and $25 \%$ stirring time. Since stirring is the main energy consumer, future work should include less energy consuming methods to suspend the digestate.

\section{Acknowledgements}

This work has been funded by Portuguese National Funds through FCT - Portuguese Foundation for Science and Technology under CERNAS (UID/AMB/00681/2013). Celia Dias-Ferreira and Verónica Oliveira have been funded through FCT "Fundação para a Ciência e para a Tecnologia” by POCH Programa Operacional Capital Humano within ESF - European Social Fund and by national funds from MCTES (SFRH/BPD/100717/2014; SFRH/BD/115312/2016). The authors would like to thank Sabrina Hvid for carrying out ICP analyses.

\section{References}

[1] Statista. Phosphate rock production worldwide in 2017, by country (in 1,000 metric tons) 2018. https://www.statista.com/statistics/681617/phosphate-rock-production-by-country/ (accessed November 23, 2018).

[2] UNEP, IFA. Environmental aspects of phosphate and potash mining. First edit. United Nations publication; 2001.

[3] BCS. Energy and Environmental Profile of the U.S. Mining Industry: Chapter 8 - Phosphates. 2002.

[4] European Union. Making energy secure, affordable and sustainable - energy union package 2015. https://eur-lex.europa.eu/legal-content/EN/TXT/HTML/?uri=LEGISSUM:1801_7\&from=EN (accessed October 24, 2018).

[5] Oliveira V, Dias-Ferreira C, Labrincha J, Kirkelund GM. Testing new strategies to improve the 
recovery of phosphorus from anaerobically digested organic fraction of municipal solid waste. $\mathrm{J}$ Chem Technol Biotechnol 2019:(Submitted).

[6] Ebbers B, Ottosen LM, Jensen PE. Comparison of two different electrodialytic cells for separation of phosphorus and heavy metals from sewage sludge ash. Chemosphere 2015;125:122-9. doi:10.1016/j.chemosphere.2014.12.013.

[7] Nystroem GM, Ottosen LM, Villumsen A, Nystroem GM, Ottosen LM, Villumsen A. Acidification of Harbor Sediment and Removal of Heavy Metals Induced by Water Splitting in Electrodialytic Remediation Splitting in Electrodialytic Remediation. Sep Sci Technol 2005;40:2245-64. doi:10.1080/01496390500201367.

[8] Sun TR, Ottosen LM. Effects of pulse current on energy consumption and removal of heavy metals during electrodialytic soil remediation. Electrochim Acta 2012;86:28-35. doi:10.1016/j.electacta.2012.04.033.

[9] Jung EJ, Moon BM, Min DJ. Quantitative evaluation for effective removal of phosphorus for SoG-Si. Sol Energy Mater Sol Cells 2011;95:1779-84. doi:10.1016/j.solmat.2011.02.001.

[10] Tan Z, Lagerkvist A. Phosphorus recovery from the biomass ash: a review. Renew Sustain Energy Rev 2011;15:3588-602. doi:10.1016/j.rser.2011.05.016.

[11] Jensen PD, Sullivan T, Carney C, Batstone DJ. Analysis of the potential to recover energy and nutrient resources from cattle slaughterhouses in Australia by employing anaerobic digestion. Appl Energy 2014;136:23-31. doi:10.1016/j.apenergy.2014.09.009.

[12] Kelly PT, He Z. Nutrients removal and recovery in bioelectrochemical systems: A review. Bioresour Technol 2014;153:351-60. doi:10.1016/j.biortech.2013.12.046.

[13] Almatouq A, Babatunde AO. Identifying optimized conditions for concurrent electricity production and phosphorus recovery in a mediator-less dual chamber microbial fuel cell. Appl Energy 2018;230:122-34. doi:10.1016/j.apenergy.2018.08.108.

[14] Elmekawy A, Hegab HM, Vanbroekhoven K, Pant D. Techno-productive potential of photosynthetic microbial fuel cells through different configurations. Renew Sustain Energy Rev 2014;39:617-27. doi:10.1016/j.rser.2014.07.116.

[15] Cai T, Park SY, Li Y. Nutrient recovery from wastewater streams by microalgae: Status and prospects. Renew Sustain Energy Rev 2013:360-9. doi:10.1016/j.rser.2012.11.030.

[16] Chang Y, Wu Z, Bian L, Feng D, Leung DYC. Cultivation of Spirulina platensis for biomass production and nutrient removal from synthetic human urine. Appl Energy 2013;102:427-31. doi:10.1016/j.apenergy.2012.07.024.

[17] Yu Y, Lei Z, Yang X, Yang X, Huang W, Shimizu K. Hydrothermal carbonization of anaerobic 
granular sludge: effect of process temperature on nutrients availability and energy gain from produced hydrochar. Appl Energy 2018;229:88-95. doi:10.1016/j.apenergy.2018.07.088.

[18] Guedes P, Couto N, Ottosen LM, Kirkelund GM, Mateus E, Ribeiro AB. Valorisation of ferric sewage sludge ashes: Potential as a phosphorus source. Waste Manag 2016;52:193-201. doi:10.1016/j.wasman.2016.03.040.

[19] Viader RP, Jensen PE, Ottosen LM, Ahrenfeldt J, Hauggaard-Nielsen H. Sequential electrodialytic recovery of phosphorus from low-temperature gasification ashes of chemically precipitated sewage sludge. Waste Manag 2017;60:211-8. doi:10.1016/j.wasman.2016.11.030.

[20] Sun TR, Ottosen LM, Mortensen J. Electrodialytic soil remediation enhanced by low frequency pulse current - Overall chronopotentiometric measurement. Chemosphere 2013;90:1520-5. doi:10.1016/j.chemosphere.2012.08.038.

[21] Sun TR, Ottosen LM, Jensen PE. Pulse current enhanced electrodialytic soil remediation Comparison of different pulse frequencies. J Hazard Mater 2012;237-238:299-306. doi:10.1016/j.jhazmat.2012.08.043.

[22] Sun TR, Ottosen LM, Jensen PE, Kirkelund GM. Effect of pulse current on acidification and removal of $\mathrm{Cu}, \mathrm{Cd}$, and As during suspended electrodialytic soil remediation. Electrochim Acta 2013;107:187-93. doi:10.1016/j.electacta.2013.05.138.

[23] Oliveira V, Labrincha J, Dias-Ferreira C. Extraction of phosphorus and struvite production from the anaerobically digested of organic fraction of municipal solid waste. J Environ Chem Eng 2018;6:2837-45. doi:10.1016/j.jece.2018.04.034.

[24] Ottosen LM, Crespo CSV, Jensen PE, Kirkelund GM, Ribeiro AB. Electrodialytic phosphorous recovery from suspended sewage sludge ash - continuous or periodical stirring. Proc Symp EREM 20172017.

[25] Ebbers B, Ottosen LM, Jensen PE. Comparison of two different electrodialytic cells for separation of phosphorus and heavy metals from sewage sludge ash. Chemosphere 2014;125:122-9. doi:10.1016/j.chemosphere.2014.12.013.

[26] Chen W, Kirkelund GM, Jensen PE, Ottosen LM. Comparison of different MSWI fly ash treatment processes on the thermal behavior of $\mathrm{As}, \mathrm{Cr}, \mathrm{Pb}$ and $\mathrm{Zn}$ in the ash. Waste Manag 2017;68:240-51. doi:10.1016/j.wasman.2017.07.011. 